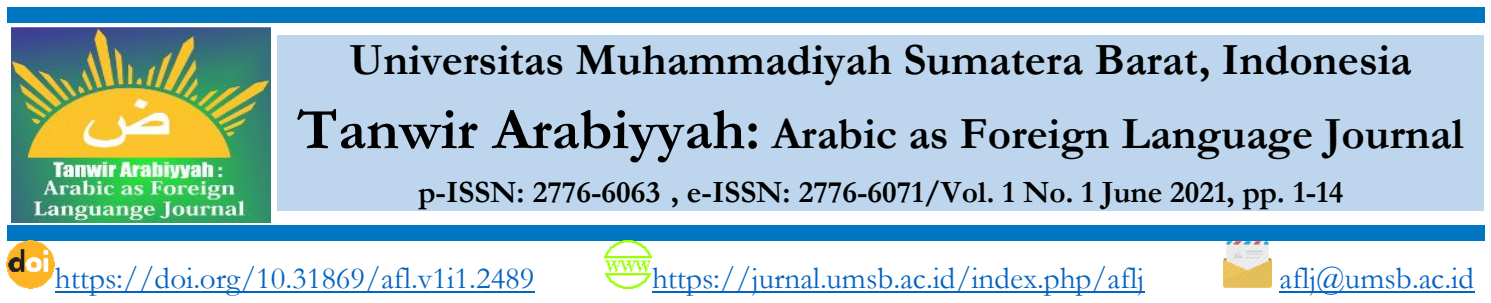

\title{
al-'Arabiyah Linnasyi'in: Analysis of Teaching Materials By Mahmud Ismail Shini, Nashif Musthofa Abdul 'Aziz, and Mukhtar Thahir Husain
}

\author{
*Adri Hidayatullah \\ STIQ Amuntai Kalimantan Selatan, Indonesia \\ andrevoyager@gmail.com
}

\begin{abstract}
ARTICIE INFO
Article History:

Received: 25 February 2021

Revised: 04 March 2021

Accepted: 01 May 2021

Published: 01 June 2021

*Corresponding author

Keyword

Learning resources are an important aspect in the learning process, various models of arabic learning resources are raised by experts in accordance with the results of their research and development. In line with that the book "al-'Arabiyyah Linnasyi'in" is one of the various sources of Arabic language learning that is widely used in educational institutions, but how the method of writing this book has not been revealed so that it is interesting for Arabic teachers to make it as a source of learning, therefore this research aims to know the form of presentation used in the teaching book "al-'Arabiyyah Linnasyi'in". This research uses qualitative descriptive approach, the data source used is the book "al'Arabiyyah Linnasyi'in", as well as other works related to the preparation of textbooks. The data is collected by carefully reading the themes related to the focus of the research. The research data was analyzed using critical analysis. The results prove that the preparation of the book al-'Arabiyyah Linnasyi'in compiled by nazhariyyah al-wihdah method and theory, this finding is based on the material on the aspect of vocabulary, sentence structure in terms of organizing material, presentation of vocabulary, presentation of structures arranged without fundamental separation, in addition the material is arranged in stages so as to allow users of this book to understand it sequentially.

Materials; Arabic Teaching; Models

Copyright (C) 2021,Adri Hidayatullah

This is an open access article under the CC-BY-SA license

\section{مستخخام البحث}

إن مادة التعليم هي جانب مهم في عملية التعلم، يتم رفع نماذج مختلفة من موارد التعلم باللغة العربية من

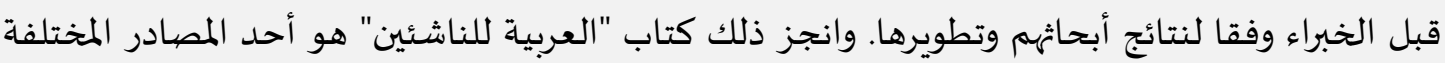

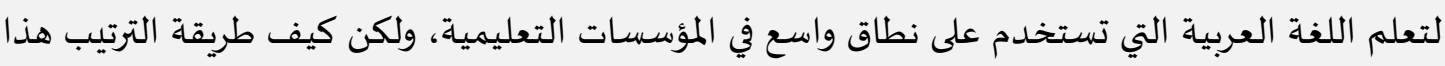

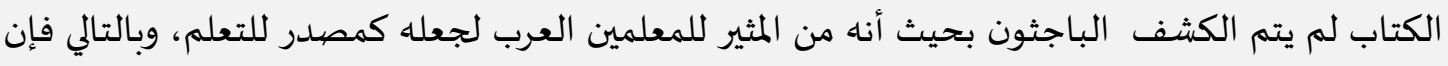

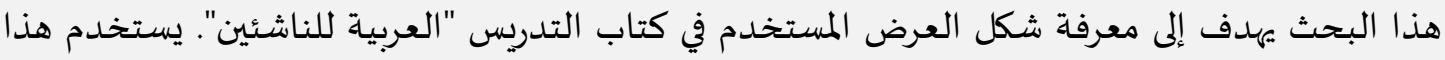

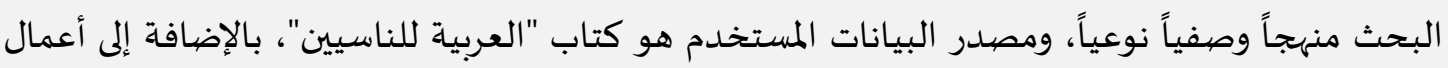


أخرى تتعلق بإعداد الكتب المدرسية. يتم جمع البيانات من خلال قراءة دقيقة المواضيع المتعلقة بتركيز

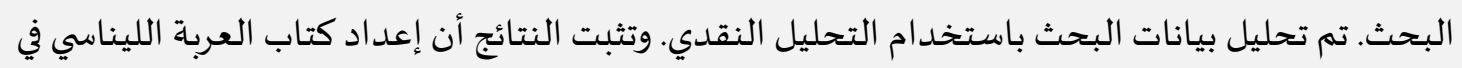

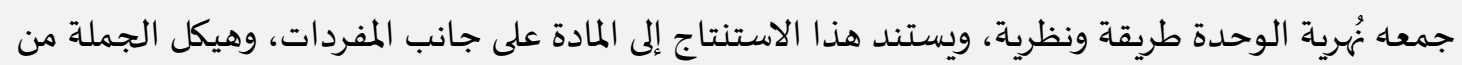

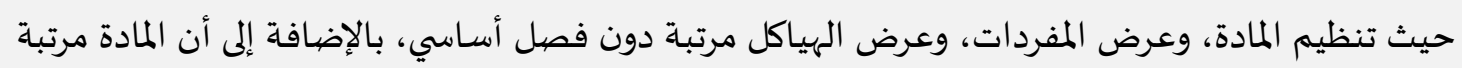
على مراحل بحيث تسمح لمستخدمي هذا الكتاب بفهمها بشكل تسلسلي.

مادة التعليم؛ تعليم اللغة العربية؛ منهج

كلمات أسـاسية

\section{المقدمـة}

لقد ازدهرت اللغة العربية في هذا العصر الحديث، وبدأ كثير من الدارسين والمتعلمين يحاولون دراسـة اللغة العربية وتعلمها.وعلى الرغم من أن تعليم اللغة العربية كلغة أجنبية مبكرا في كثير من البلدان الأوروبية (Sover \& Din, 2018) والأمريكية (Brosh, 2019) وآسيا وبلاد العالم الإسلامي غير الناطقين بالعربية لم يظهر الاهتمام العظيم إلا في وقت حديث نسيا(Taufiq, 2018) . وقد وجد الباحث في هذا العصر الحديث كثيرا من الفئات التى تهتم بتعليم اللغة العربية، من هذه الفئات، المسلمون من غير العرب، وأعضاء البعثات الدبلوماسية والتعليمية، ورجال الأعمال، والآخر (Omar, 2017) . لكن المشكلة التى تواجه هؤلاء جميعا هو عدم وجود المنهج الدقيق لتعليم هذه اللغة، وعدم وجود الكتب الجيدة المحققة لهذا الغرض.

وإذا نظرنا من المدارس والمعاهد في هذا العصر الحديث، أن تعليم اللغة العبية لغير

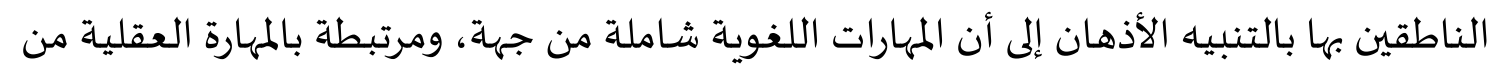
جهة أخرى. ولكن بشكل عام أو ما يهم في طرق تدريس اللغة العربية يمكن تحديد بعض المهارات اللغوية الضرورية في مراحل التعليم الثلاثة المعروفة وهي مهارة الاستماع، ومهارة القراءة، ومهارة الكلام، ومهارة الكتابة. ('Abdurrahman, 2018)

انطلاقا من الأمور السابقة ووجود الطريقة الحديثة في تعليم اللغة العربية ظهر الكتاب

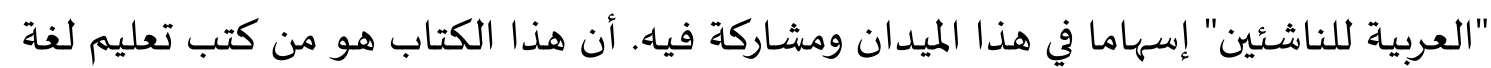
العربياة لغير الناطقين بهابالتكامل بين مهارات المختلفة من استماع وكلام وقراءة وكتاباة.والاهتمام باللغة العربية مع مراعاة الثقافة الإسلامياة ليتمكن الدارس من استعمال ما يتعلماه في فهم الدين الإسلامي والاتصال في شؤون الحياة اليومية. وهو الذي يساعد سرعة تعلم اللغة العربية لغير الناطقين بها.

واستخدم المؤلف في تأليف هذا الكتاب منهجا خاصا بحيث في تنظيم الكتابة والمواد الدراسية، ليكون معلم اللغة العربية يشعر بسهلة في تعليم اللغة العربية. وهذا الكتاب مهم ملائق 
ومطابق لتعليم اللغة العربية لغير الناطقين بها. لأن يأتي فيه بأنواع التسهيلات في تعليم اللغة

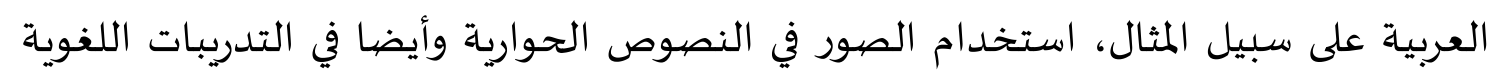
والتعبير الشفوي، وتدور الحوارات والموضيوعات من الأنشطة يواجهها التلاميذ في محيطهم وبيئتهم كل يوم، وفياه أنواع أخرى من التسهيلات.

وتدرس هذا الكتاب في بعض مدارس ومعاهد وجامعات، ومازالت تستخدم هذا الكتاب كإحدى الكتب الأسـاسية لتعليم اللغة العربية لغير الناطقين بها. وقد ألف المؤلف هذا الكتاب

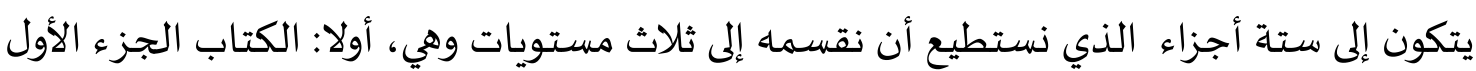

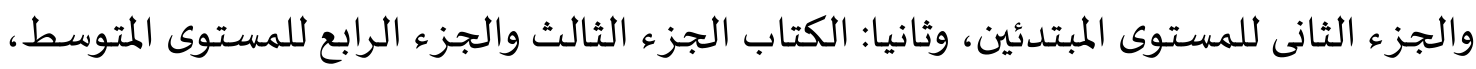
وثالثا: الكتاب الجزء الخامس والجزء السـادس للمستوى المتقدم) (Husni, 2014) .

فأهمية هذا الكتاب وشيوع استخدامه ولعدم كتابة منهجه، فأراد الباحث معرفة منهج هذا الكتاب. وفي هذا البحث أراد الباحث أن يهتم بمنهج كتابين الجزء الأول والجزء الثاني من هن كتاب "العربية للناشئين" بأجزائه الستاة، حيث أن هذين الكتابين تخصص للمتعلمين المبتدئين الذي يؤكد على الجانب الشفهي.

\section{طريقة البحث}

ليتم هذا البحث، قام الباحث باستخدام طريقة المكتبي الوصفي، اهداف استعمال هذا المنهج الوصفي هي أن من اهم اهداف الاسلوب الوصفي في البحث هو فهم الحاضر من اجل توجياه المستقبل . فالبحث الوصفي يوفر بيانتاه وحقائقه واستنتاجاته الواقعية باعتبارها خطوات تمهيدية لتحولات تعتبر ضرورية نحو الافضل ويمكن اجمال اهداف الاسلوب الوصفي في النقاط التالية: 1. جمع بيانات حقيقية ومفصلة لظاهرة او مشكلة موجودة فعلا لدى مجتمع معيل معين. 2. تحديد المشكلات الموجودة وتوضيحها . 3. اجراء مقارنات لبعض الظواهر او المشكلات وتقويمها وايجاد العلاقات بين تلك الظواهر او المشكلات. 4. تحديد مايفعله الافراد في مشكلة او ظاهرة ما والاستفادة من ارائهم وخبراتهم في وضع تصور وخطط مستقبلية واتخاذ القرارات المناسبة لمواقف

متشابهة مستقبلا.

\section{حصيول البحث وتحليلها}

ظهر المؤلف في تأليف هذا الكتاب بتقديم على الحوار الذي يدل اهتمامه نحو مهارة الكلام والاستماع. وكان الحوار يستخدم بالكلمة السهلة مع يصاحب الصيورة جانب مقالة الحوار مطابقا بالموضوع توضيحا لقصد الحوار. وكانت الصيورة الموجودة ممتازة ومشوقة مملوءة بالألوان 
وعرضت الصورة ليس في الحوار فحسب بل تعرضفيه مناسبابالنصوص القرائية والتدرببات

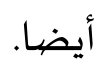

واستخدم المؤلف اللغة العببية الفصيحة التى يكتسبها الطالب عن طريق التدرج من المنال

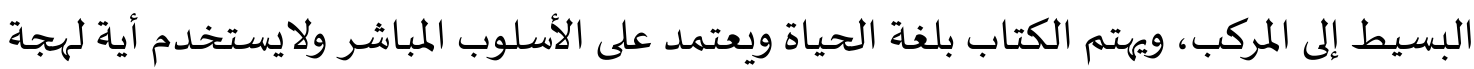

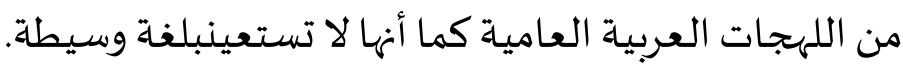

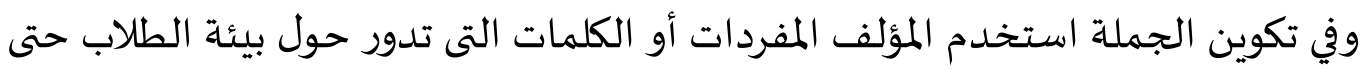

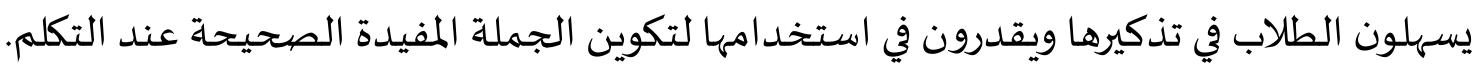

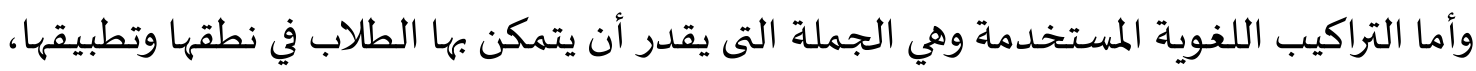
حتى يتعود بها الطلاب استخدامها في أنشطة أيامهم.

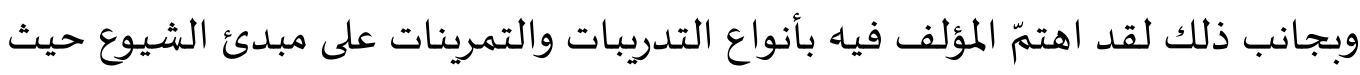

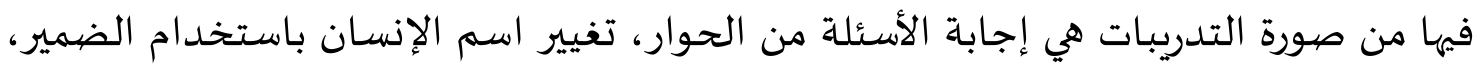

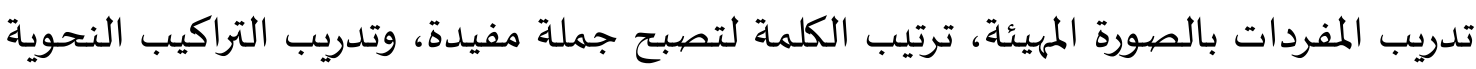

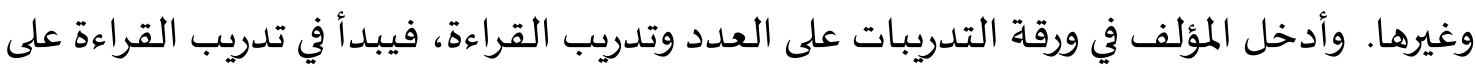
قراءة الكلمة إلى الجملة وكتابتها حتى نص القراءة، وذلك لتدريب على مهارة المباء القراءة. وتخصص المؤلف آخر كل الوحدة في هذا الكتاب على تدريبات الكتابة. وكان التدريب

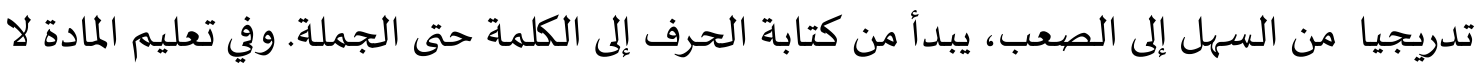

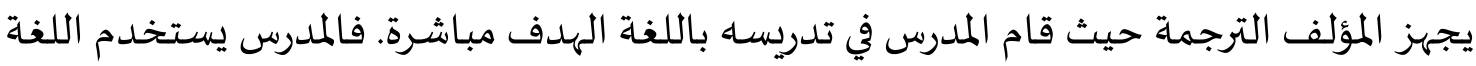

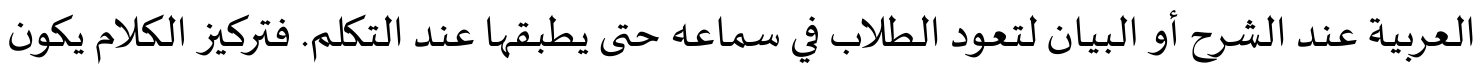

$$
\begin{aligned}
& \text { الهدف الأساسي في تعليم هذا الكتاب. }
\end{aligned}
$$

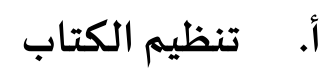

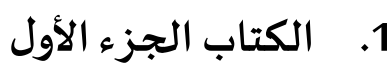

لقد تم تصميم كتاب "العربية للناشئين" الذي ألفه الأستاذ محمود اسماعيل صيني

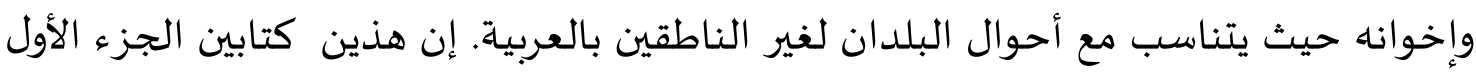

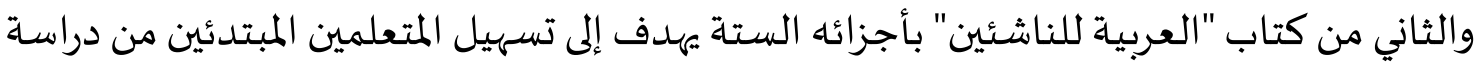

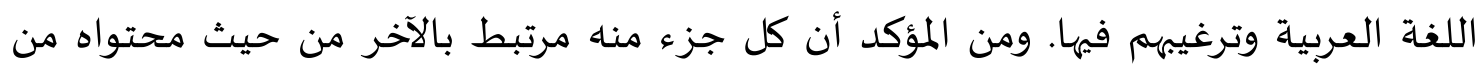

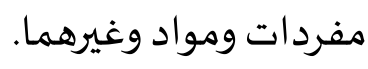

وقد بدأ الجزء الأول في الوحدات الخمس الأولى من القسم الأول والثاني والثالث والرابع

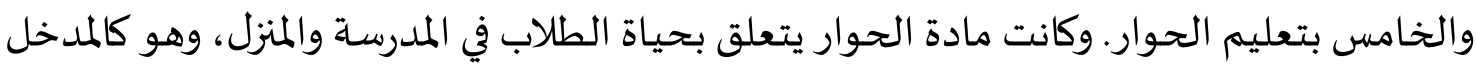


الأساسي في تعليم هذا الكتاب. فيؤمن الكتاب أن تعلم اللغة والتقدم فيما إنما يتحقق بالتدريب

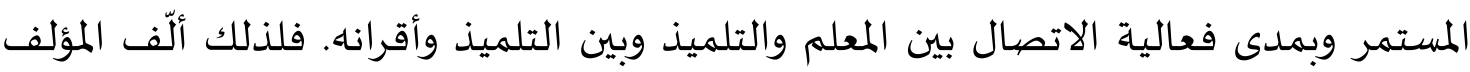

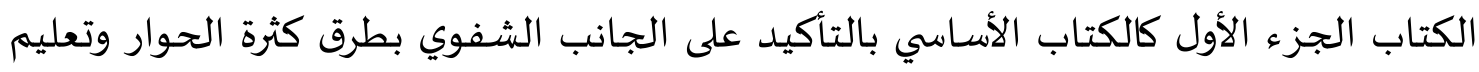

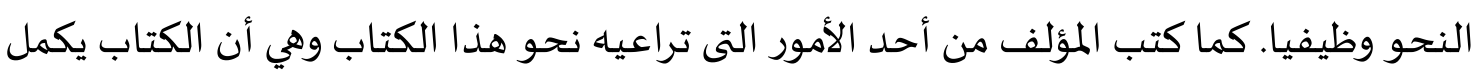

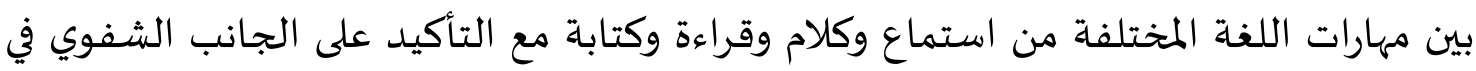
الكتابين الأول والثاني بصورة خاصة.

إن هذا الكتاب يختص إلى المتعلمين المبتدئين حيث يسهلهم في تعلم اللغة العربية خاصة في

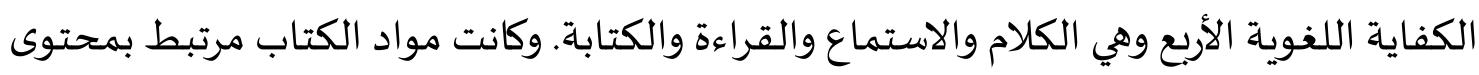

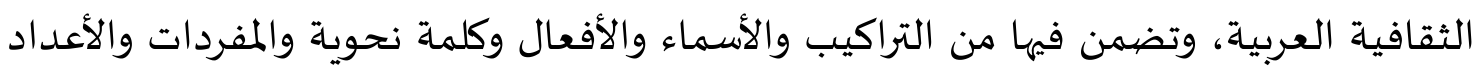
وتعبيرات والأصهوات وغير ذلك يشمل بعضهم من بعض. ويتم تطبيق كلها في الحوار والتدريبات

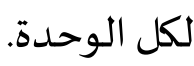

توسيعا مما سبق، فقد جاء المؤلف في القسم الأول على أن الحوار والتدريبات تعتمد على والى

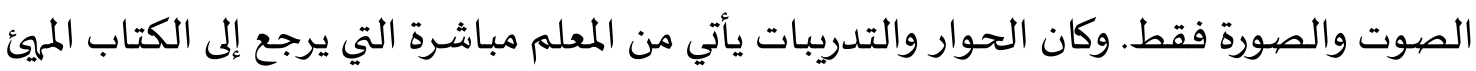

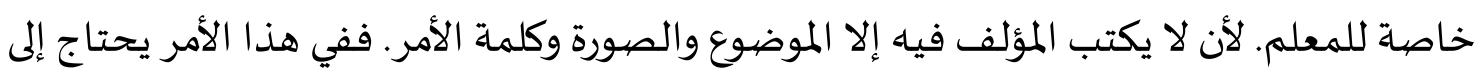

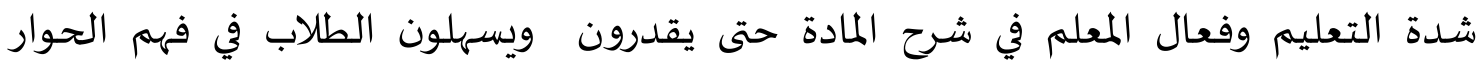
والتدريبات.

ويتم تطبيق كل الكلمة النحوية من القسم الأول في الحوار لكل الوحدة على طريقة

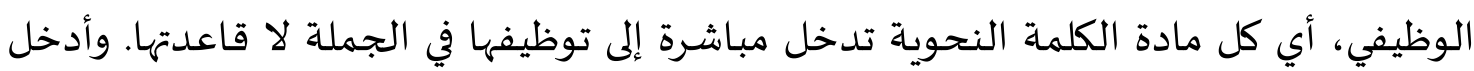

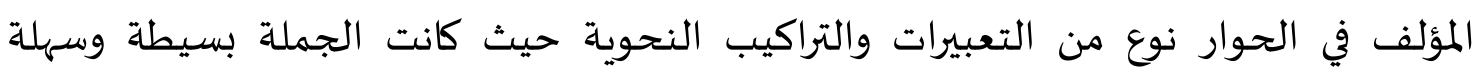

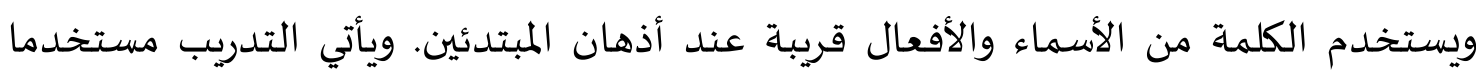

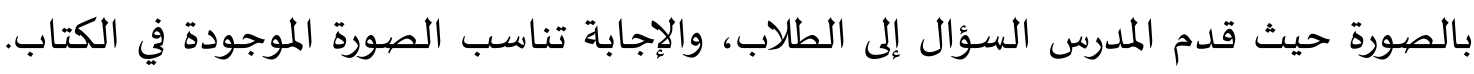

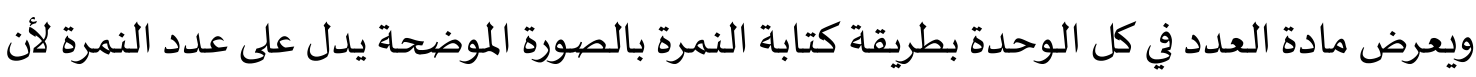

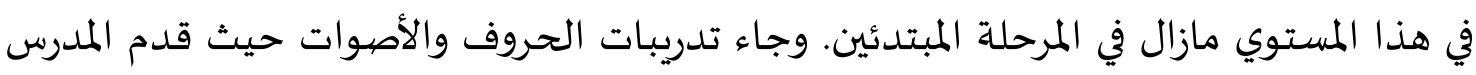

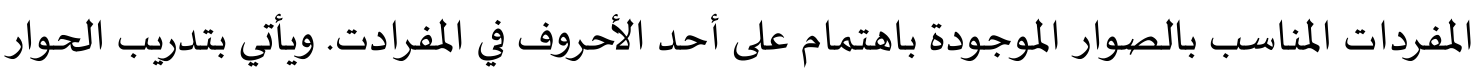

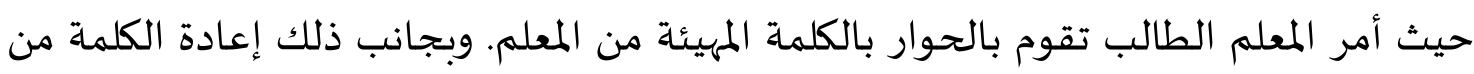

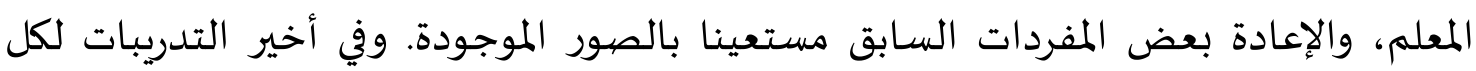

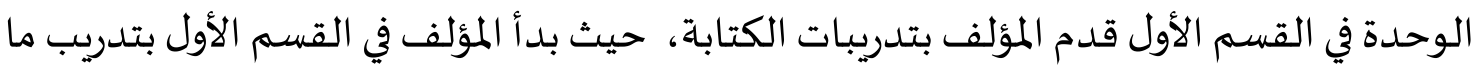

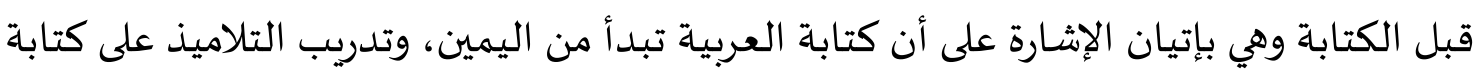


أحرف الهجائية حرفا فحرفا وكتابة الحركات. وأما في الوحدة السادسة مراجعة ما درس في الوحدات الخمس السابقة لها.

وأما في القسم الثاني والثالث والرابع والخامس يقوم الحوار يعتمد على الصيوت والصهورة

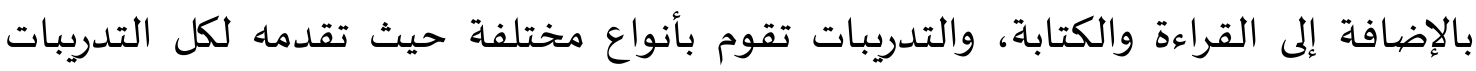
بالأمثلة، وتكون المواد لكل الوحدة مرتبطة بالوحدات الأخرى من الكلمة النحوية والمفردات والآخر. وإلى جانب ذلك، عرض المؤلف في القسم الثاني ضمير "هو، أنا، أنتَ، أنتِ" حيث وضيعاه في

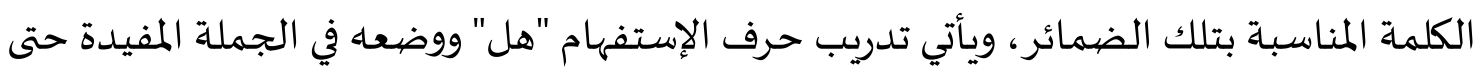

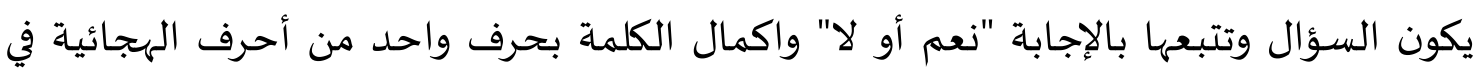

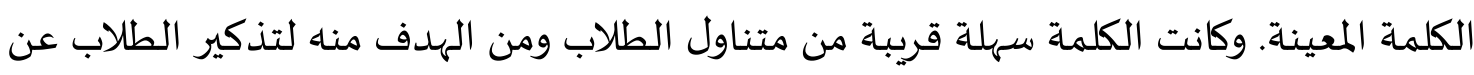

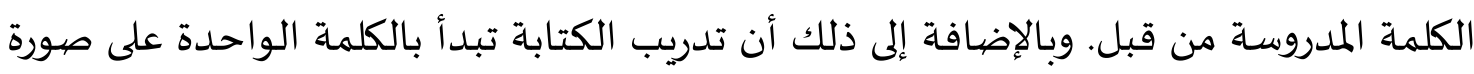
الفعل والإسم.

ويعلم في القسم الثالث عن الإسم الإثـارة ومضاف إليه حيث وضيعهما في الجملة المفيدة

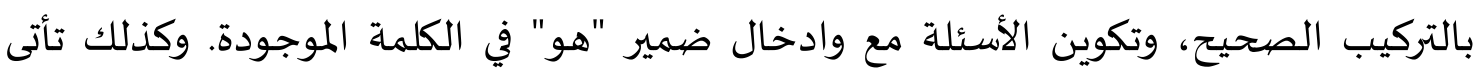

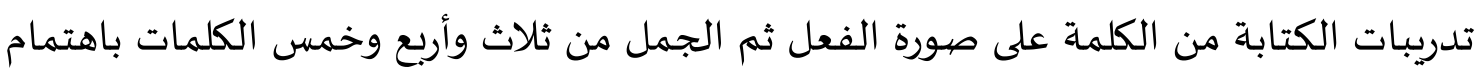

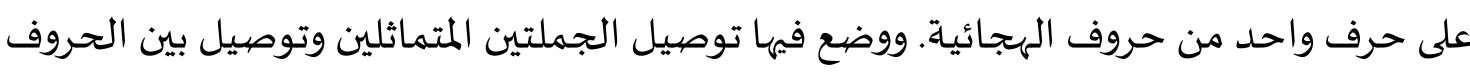
في صورة الفعل وكذلك اختيار السؤال والجواب المناسب.

ويأتي في القسم الرابع إجابة الأسئلة مستعينا بالأرقام الموجودة حيث أمر المؤلف بتغيير

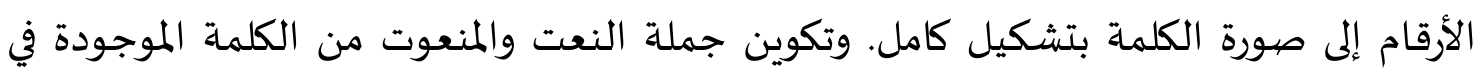

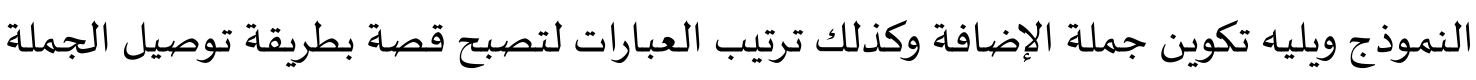

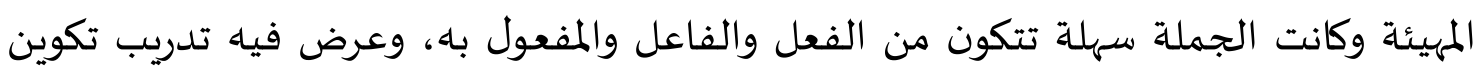

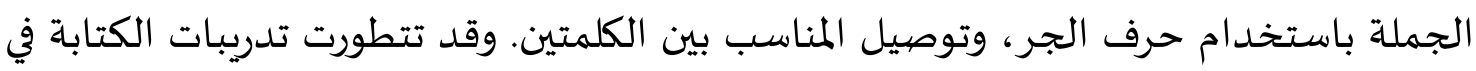

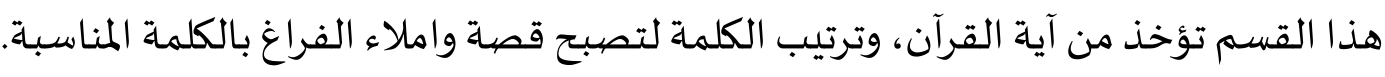
اختص في القسم الخامس بالحوارين في كل الوحدة لتدريب كفاءة اللغوية من ناحية

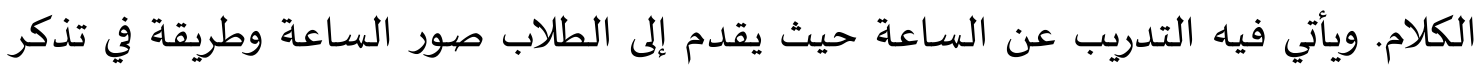

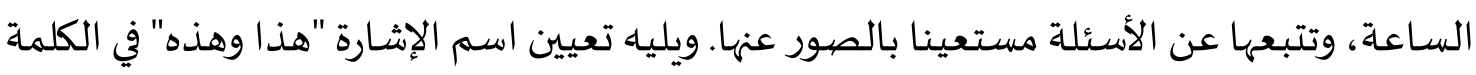

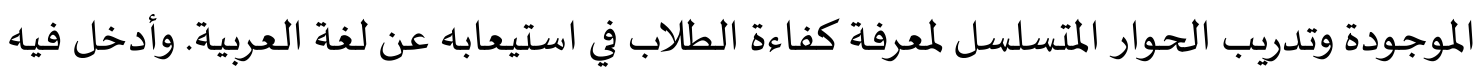

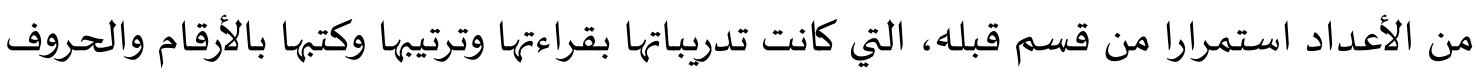

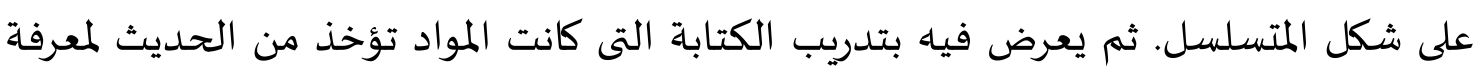


معيار قدرة التلاميذ في الكتابة. وزاد المؤلف في أخير كل قسم بنص قرائي لتثبيت ما درس في الحوارات السابقة، وكذلك للتدرببات والمراجعة بما درساء من قبل.

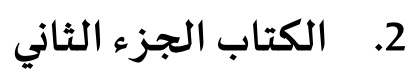

من ملاحظة الباحث أن الكتاب الثاني لا يزال يدور حول ما يعرض في الكتاب الأول، إلا أن المؤلف قام بتوسيع النطاق، وحاول في الربط فيما بينهما. وذلك عن طريق تكرار ما في الكتاب الأول

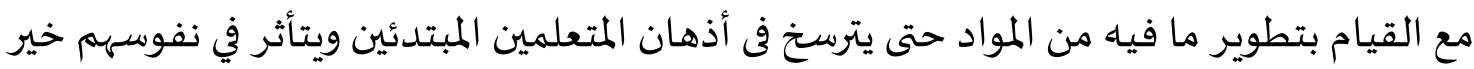
التأثير.

وقد زاد المؤلف في الكتاب الثانيبنص القراءة في كل الوحدة حيث يعرض فيه تدريب النحو وظيفيا والتعبيرات التى لم يسمعها الطلاب من قبل، ويتبع بعد ذلك بالأسئلة عما يتعلق بهاه. وبجانب ذلك تطور تعليم الكتابة بفنون الجميلة بالقاعدة الصحيحة بخط الرقعاة ليتمكن

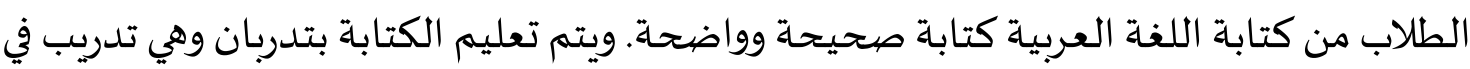
نسخ خط الرقعة وحدة وتدريب الإملاء حيث تعالج معظم القواعد الإملائية. والجدير بالإشارة هنا إلى أن معظم المواد في هذا الجزء خاصة تلحقها أسئلة لها والتى يقصد بها تقييما لمدى فهم الطلاب المبتدئين عن الدرس، حتى تكون المواد لا يبعد عن الكتاب الأول لسهولة الطلاب في تذكيرها وتطبيقها واستخدامها في أنشطتهم.

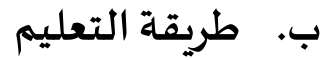

هي عبارة عن خطة عامة لاختيار وتنظيم وعرض المادة اللغوية، على أن تقوم هذه الخطة

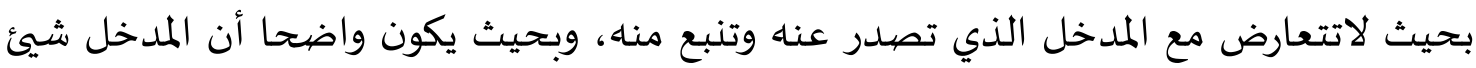

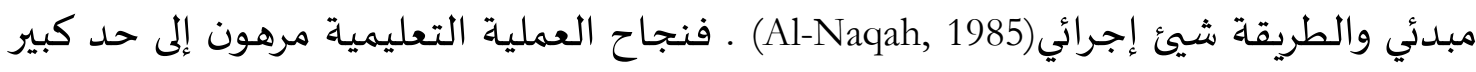

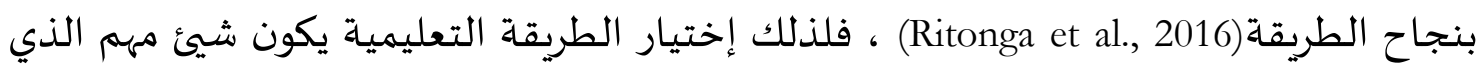
لابد أن يراعياء قبل بداية الدراسة.

فمن ملاحظة الباحث في تنظيم مادة كتاب "العربية للناشئين الجزء الأول والثاني" ظهر أن

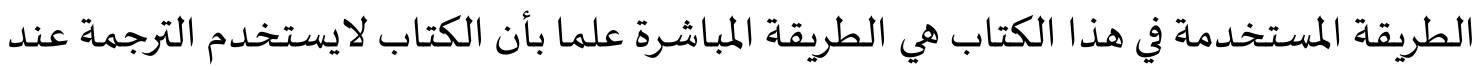

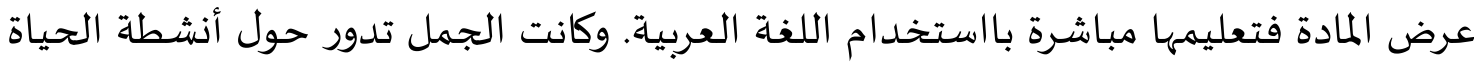

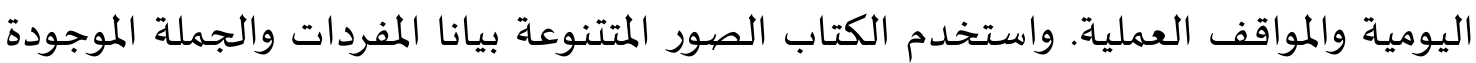

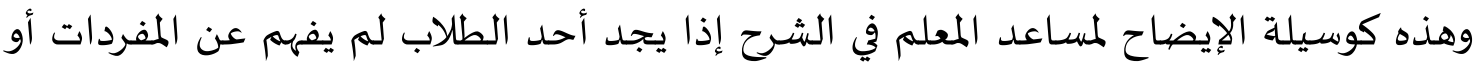

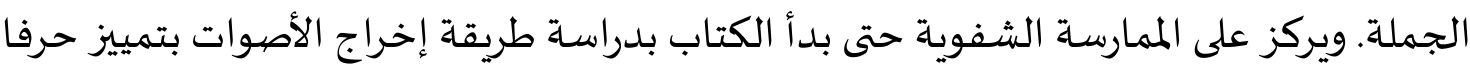
فحرفا من أحرف الهجائية حيث مخرجها ووضع الحوار أو المحادثة في كل موضيوعها. 
وقد استندت هذه الطريقة على نظرية أساسها أن التلميذ يمكن أن يتعلم منذ البداية أن

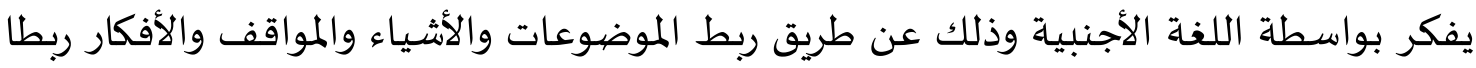

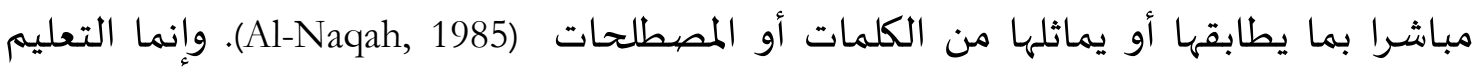

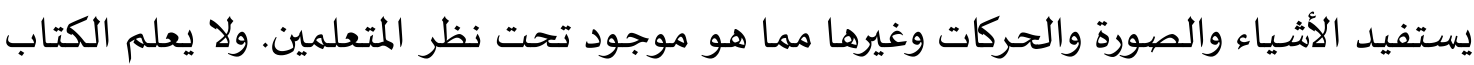

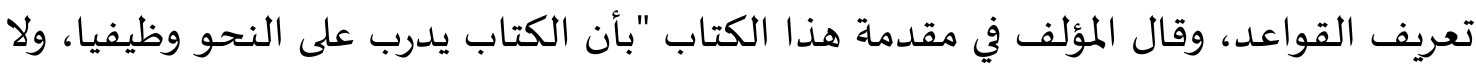

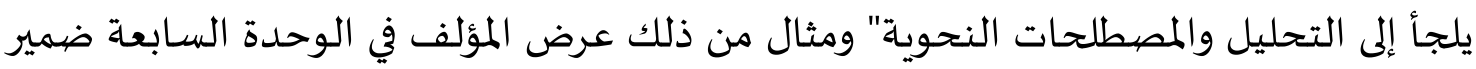
هو، فالمادة تدخل مباشرة إلى توظيفها في الجملة لا قاعدتها. ج. المفردات

تبدأ المفردات في الكتاب العربية للناشئين تدريجيا من السهل إلى الصعب حول موضوعات

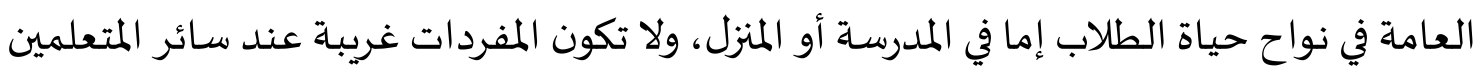

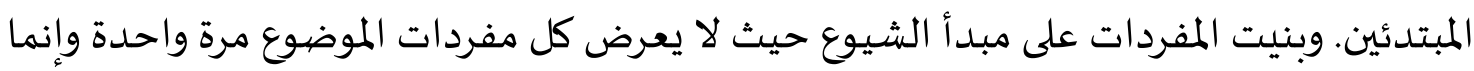
يعرضها على دفعات، وبمجموعات مترابطة، بهدف الاستعمال وليس الحفظ والاستظهار I. Shini

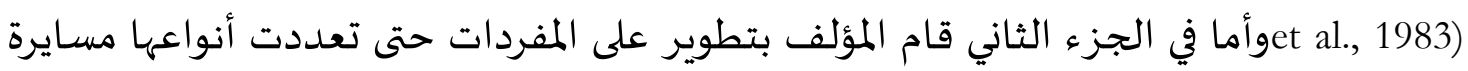

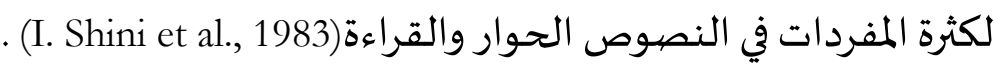
فتناول الباحث الأمور المهمة عن مفردات الكتاب، وهي ما يلي 1. يصاحب المفردات الصورة

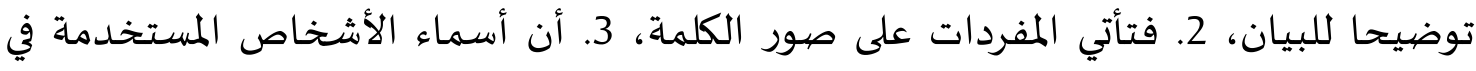
الكتاب من أسماء الإسلام، 4. أن أسماء البلدان المستخدمة في في الكتاب من أسماء بلدان المانداء الإسلام.

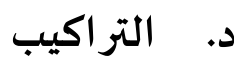

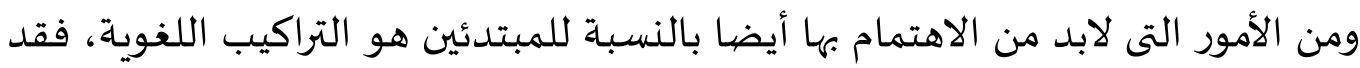

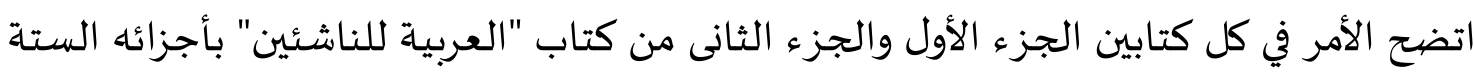

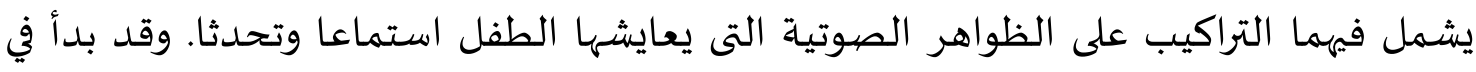

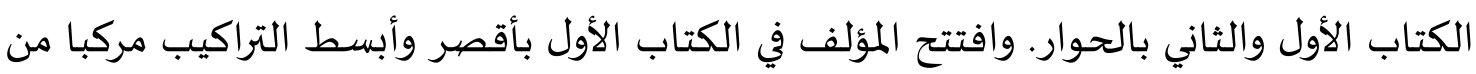

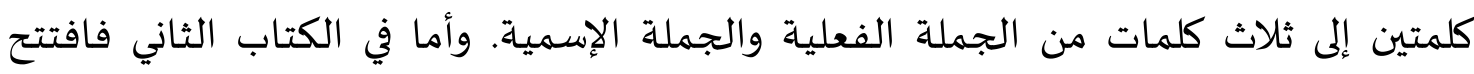

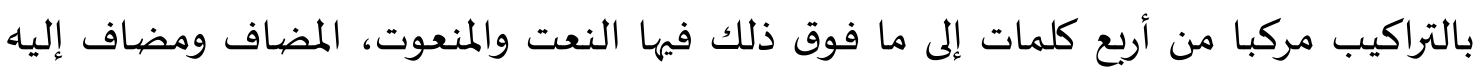
والظرف.

\section{هـ الصور}

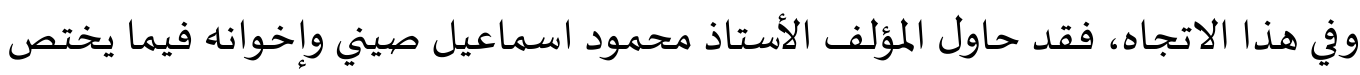

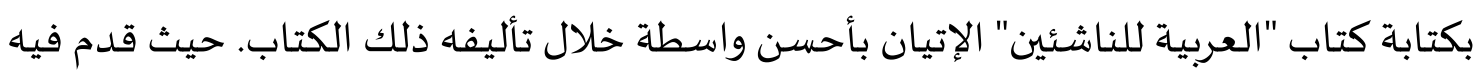


عدة صور مختلفة وموضحة تناسب بالنصوص الحوارية والقرائية والتدريبات، وكان وجود الصورة ليبين كل الجملة في الحوار والنصوص القرائية وكذلك التدريبات حتى يسهل المدرس على الشرح ويساعد التلاميذ على الفهه.

ومن خلال البحث وجد الباحث أن هذا الكتاب يأتي بصورة وظيفية، وكل صورة وظيفية ممتازةوقريبة في ذهن الطلاب. وتعبر الصورة لتوضيح عن الموضوع المستهدف وتشمل الموضوع أكثر من صورة حتى يسهلهم الطلاب في فهم ما يقرؤون. و. التدرببات

وضع المؤلف التمرينات أوالتدريبات في كتاب "العربية للناشئين" الجزء الأول والثاني عناية خاصية للتدريب بمختلفة أنواعه وأشكاله، ويعتبره الوسيلة الأسـاسية في تعليم اللغة.ويأتى الكتاب التدريبات متدرجا في كل المهارات من البسيط إلى المركبحيث كانت تناسب بمرحلة المبتدئين.وكانت التدريبات لا تتجاوز قدرات قياسية الطلاب المبتدئين، إفتتحت التدريبات في الكتاب الأول بتعليم

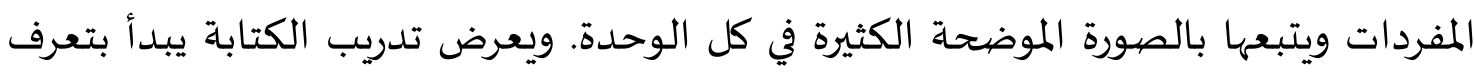
أحرف الهجائية مع تشكيلها حيث لايصعب الطلاب عنها. وتتطور التدرببات في الكتاب الثاني

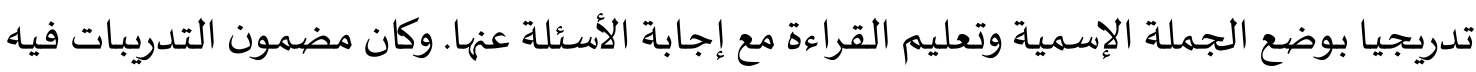

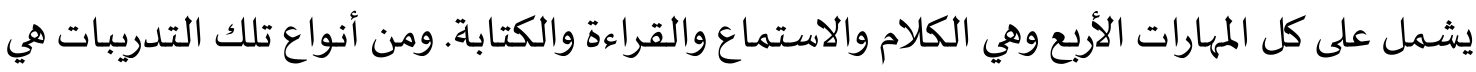
تدريب الكلام التى تبدأ من السؤال والجـواب، وتدريب الحوار المتسلسل، وتدريب إكمال الحوار. وتدريب الاستماع التى تبدأ التدريبات على مستوى الكلمة، ثم الجملة والعبارة ثم الحوار والنص. ويأتى تدريب القراءة التى التدرج على مستوى الكلمة والجملة والنص. وتدريب الكتابة التى تبدأ من نسخ الكلمة والجملة، وكتابة الحرف الناقص، والإملاء، وغير ذلك.ومن تفاصيل التدرببات في هذين كتابين كما يلي:

التدريبات في كتاب الأول(M. I. Shini et al., 1983)

\begin{tabular}{|c|c|}
\hline أنواع التدريبات & التدريبات \\
\hline تجريد الحروف & \\
\hline التمييز بين الأصهوات & \\
\hline الظواهر الصيوتية مثل "التنوين" & \\
\hline التعرف على الكلمات & \\
\hline الـ الشمسية و الـ القمرية & \\
\hline التعرف على الجـمل & \\
\hline
\end{tabular}




\begin{tabular}{|c|c|c|}
\hline وصل الحروف كلمة فيها الحرف & $\begin{array}{l}.7 \\
.8 \\
\end{array}$ & \\
\hline مل الإجابة عن أو خطأ أسئلة النص & $\begin{array}{l}.1 \\
.2 \\
.3\end{array}$ & تدرببات الاستيعاب \\
\hline 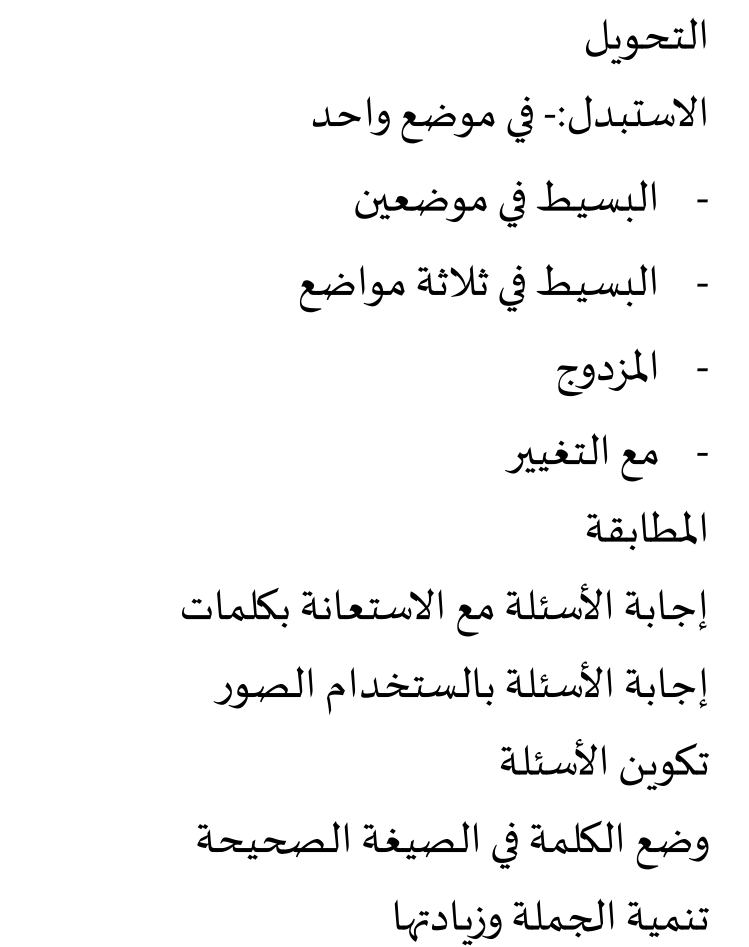 & $\begin{array}{l}.3 \\
.4 \\
.5 \\
.6 \\
.7 \\
.8\end{array}$ & تدريبات النحو \\
\hline 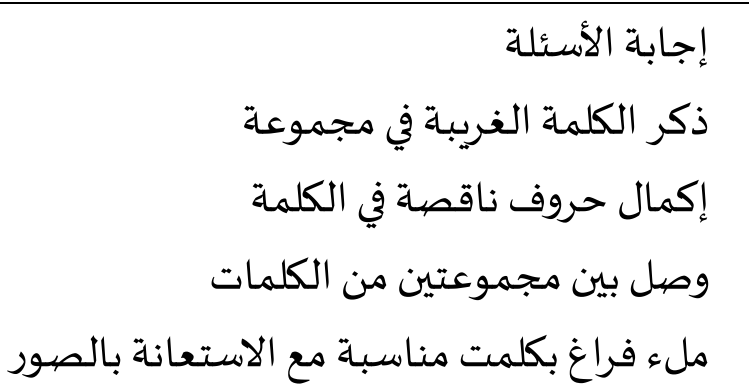 & $\begin{array}{l}.1 \\
.2 \\
.3 \\
.4 \\
.5\end{array}$ & تدريبات المفردات \\
\hline 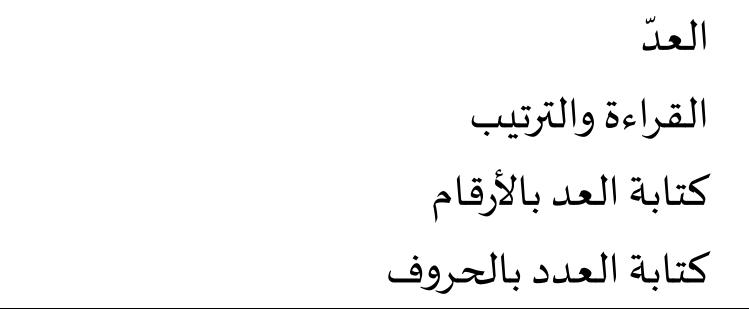 & $\begin{array}{l}.1 \\
.2 \\
.3 \\
.4\end{array}$ & تدريبات الأرقام والأعداد \\
\hline $\begin{array}{r}\text { أجراء الحوار } \\
\text { الحوار المتسلسل }\end{array}$ & $\begin{array}{l}.1 \\
.2\end{array}$ & تدريبات الاتصيال \\
\hline
\end{tabular}




\begin{tabular}{|c|c|c|}
\hline إكمال الحوار & .4 & \\
\hline ترتيب الكلمات & .1 & \multirow{5}{*}{ تدربيات التعبير } \\
\hline ترتيب العبارات & .2 & \\
\hline الوصل بين مجموعتين من العبارات & .3 & \\
\hline تكوين الجمل بالاستعانة ببعض الكلمات & .4 & \\
\hline إكمال الجمل إلمل & .5 & \\
\hline النسخ & .1 & \multirow{3}{*}{ 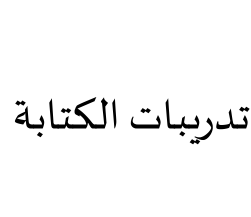 } \\
\hline كتابة الحرف الناقص & .2 & \\
\hline إملاء & .3 & \\
\hline وصل بين حروف لتكوين كلمات & .1 & \multirow{5}{*}{ الألعاب اللغويـة } \\
\hline إكمال رسم شيئ وكتابة اسمـا & .2 & \\
\hline هل تعرف & .3 & \\
\hline تنفيذ التعليمات & .4 & \\
\hline ل لعبية "الرموز" & .5 & \\
\hline
\end{tabular}

التدريبات في كتاب الثاني(M. I. Shini et al., 1983)

\begin{tabular}{|c|c|}
\hline أنواع التدريبات & التدريبات \\
\hline 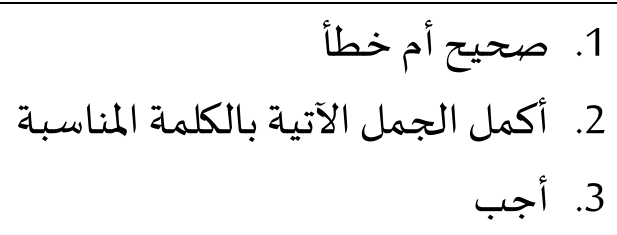 & تدريبات استيعابية \\
\hline 3. 1. 3. الاستبدال التحويل & تدريبات نحوياة \\
\hline 4. 1. 1. أجراء الحوار المتسلسل & تدريبات اتصالية \\
\hline
\end{tabular}




\begin{tabular}{|c|c|}
\hline 6. أخبر جارك ليخبر المعلم & \\
\hline 1. ضع بين الكلمات المضادة في المعنى & تريبات دلاليـة \\
\hline 1. 1 تدريب الخط الخديب الإملاء & تدريبات كتابية \\
\hline 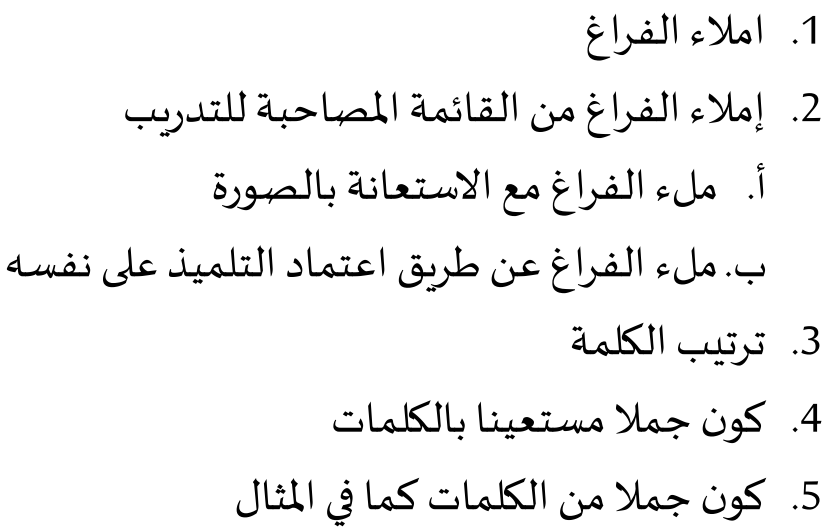 & تدريبات تعبيرية \\
\hline
\end{tabular}

\section{الخلاصية}

من خلال هذا البحث رأى الباحث أن الكتاب العربية للناشئين الجزء الأول والثاني يتناول الأمور الآتية:1) تنظيم الكتاب؛ بملاحظة الباحث، أن كل ما في كتابين الجز الأول والجز الثانى من كتاب "العربية للناشئين" بأجزائه الستة، بدأ من البسيط إلى المركب، ومن الأشياء الأقراب من أذهان الطلاب أولا ثم الأبعد، وكل جزء مناه مرتبط بالآخر. ثم إن بعض مواد الكتاب متماثل ومترابط فيما بينهما بل إنما في الثاني زيد فيما لم يذكر في الأول، وكذلك أناه تطويرا وتطبيقا عن المواد نفسها. كما زاد بما دون ذلك؛ كالنصوص القرائية باعتباره جزءا للتدريبات والتطوير والتطبيق لما كان عليه في الأول.2) المفردات، تبدأ تدريجيا من السهل إلى الصعب حول موضوعات العامة في نواح حياة الطلاب إما في المدرساة أو المنزل. ولا يعرض كل مفردات الموضوع مرة واحدة وإنما يعرضها على دفعات، وبمجموعات مترابطة، بهدف الاستعمال وليس الحفظ والاستظهار. 3) والتراكيب اللغوية؛؛ يستخدم الكتاب التراكيب اللغوية السهلة قريبة من متناول الطلاب المبتدئين. وافتتح المؤلف في الكتاب الأول بأقصر وأبسط التراكيب مركبا من كلمتين إلى ثلاث كلمات من الجملة الفعلية والجملة الإسمية. وأما في الكتاب الثاني فافتتح بالتراكيب مركبا من أربع كلمات إلى ما فوق ذلك وبنيت التراكيب النحوية على مبدأ الشيوع حيث كان يدرب الكتاب النحو 
وظيفياولايلجأ إلى التحليل والمصطلحات النحوية. 4) التدريبات؛ تأتى التدريبات متدرجا في كل المهارات من البسيط إلى المركب التى تناسب بمرحلة المبتدئين حيث كانت تشمل على كل المهارات الأربع وهي الاستماعوالكلام والقراءة والكتابة.5) منهج التعليم باستخدام الطريقة الحديثة أي الطريقة المباشرة علما بأن الكتاب لايستخدم الترجماة عند عرض المادة ويستخدم الصور المتتنوعة كوسيلة الإيضاح، ويركز على الممارسـة الشفوياة.

\section{BIBILIOGRAPHY}

'Abdurrahman, H. M. (2018). Thara'iq Haditsah fi Ta'lim al-Lughah al-'Arabiyyah. Dar al-Jadid Linnasyr wa al-Tawzi'.

Al-Naqah, M. K. (1985). Ta'lim al-Lughah al-'Arabiyyah Linnathiqin bi Lughat Ukhra UsusubMadkhaluh-Thuruq Tadrisuh. Jami’ah Um Al-Qura.

Brosh, H. Y. (2019). Arabic Language-Learning Strategy Preferences Among Undergraduate Students. Studies in Second Language Learning and Teaching, 9(2), 351377. https://doi.org//10.14746/ssllt.2019.9.2.5

Husni, A. (2014). Pembelajaran Bahasa Arab untuk Pemula (Studi Analisis Buku Al arabiyyah Linnasyi'in). Analisis, II(2), 1-13.

Omar, T. (2017). Culture and Second Language Aquisition: Arabic Language as a Model. European Scientific J, 13(2), 159-166. https://doi.org/10.19044/esj.2016.v13n2p159

Ritonga, M., Nazir, A., \& Wahyuni, S. (2016). Pembelajaran Bahasa Arab Berbasis Teknologi Informasi dan Komunikasi. Arabiyat: Jurnal Pendidikan Bahasa Arab Dan Kebahasaaraban, 3(1), 1-12. https://doi.org/http://dx.doi.org/10.15408/a.v3i1.2879

Shini, I., 'Aziz, N. M. 'Abdul, \& Husayn, M. al-T. (1983). al-'Arabiyyah Linnasyi'in (1st ed.). Wizarah al-Ma'arif.

Shini, M. I., 'Aziz, N. M. 'Abdul, \& Husayn, M. al-T. (1983). al-'Arabiyyah Linnasyi'in Juz 1 (1 st ed.). Wizarah al-Ma'arif.

Sover, A., \& Din, G. N. El. (2018). The relation between teaching the Arabic language using humour and reading comprehension at Elementary School in the Arab Sector in Israel. European Journal of Humour Research, 6(3), 94-108. https://doi.org/10.7592/EJHR2018.6.3.sover

Taufiq, M. A. (2018). Manhaj Ta'lim al-'Arabiyyah li Aghradh Khashshah, Khashaishuh wa Musykilatuh. Arabia : Jurnal Pendidikan Bahasa Arab, 10(2), 1-19. https://journal.iainkudus.ac.id/index.php/Arabia/article/view/4275/pdf 
